Editorial

\title{
A long way to go
}

\author{
Saurav Arora \\ International Journal of High Dilution Research - Editor-in-Chief
}

International Journal of High Dilution Research (IJHDR, HD) published by Groupe International de Recherche sur I'Infinitésimal (GIRI), is a well-established name in homeopathy. HD started its journey under the able guidance Dr. Carlos Renato Zacharias in 2008, and since then the journal achieved the three most important attributes for a scientific publication: readability, respect, and citation.

GIRI and Dr. Zacharias has now entrusted me with the responsibility of maintaining HD standards and carrying on the tradition of timely and quality publications. It is a matter of honour for me to join as the new Editor-in-chief of HD. I am grateful and humbled for this entrust GIRI has bestowed upon me. My association with HD editorial members Dr. Zacharias, Dr. Leoni Bonamin and Dr. Silivia Waisse has been a learning experience, and I aim to fully use this experience, to meet the new expectations.

In the next few years we aim to achieve new milestones for HD. One of the important and controversial issues with a journal now a day is the impact factor (IF). Many a times, IF and indexing remains a barrier between authors and a journal, particularly in academic peers and recruitment bylaws, although the issue is fiercely debated worldwide.

IF should not be the only matter of concern while submission of an article to a journal. It is worth quoting here that "Editors desiring to increase their influence will need to focus on a fast and friendly submission and review process, early online and speedy print publication, and encourage the rapid turnaround of high-quality peer reviews [1]'. But nonetheless, we are ready to deal IF issue in a logical and ethical way. Our aim is now to get HD indexed in major biomedical databases in next couple of years.

Second important issue is the transition of HD to its own dedicated domain i.e. www.highdilution.org, which we have successfully achieved. We aim that this will hasten the online publication and sharing easy, quick and personalised. We also expect that this step will encourage more submissions, in an easy and quick manner. Our open access policy and quick review allows wider dissemination of the published work.

Down the line our next major objective would be to increase the reader/author participation in HD. Book review, thesis indexing, case discussions and forums are few of popular scientific communication and we aim to explore these options for the HD through our online platform.

Another important issue for a journal is quality and interesting article. A scientific article cannot be cooked, rather it is the reflection of research and efforts one puts in. HD not only supports publications of quality articles, but also believes in taking remedial measures. In next few years our target is to educate fraternity about scientific study design, research methodology, conduct, analysis, and publication. 
Together with Dr. Zacharias, I would like to welcome the new editorial committee members who begin their tenures with me. Most of the existing members will continue in their positions, as their experience of the last few years is invaluable. I would also like to thank all our readers, authors, and reviewers for their support of the journal. Our aim to be the pre-eminent bio-medical journal is only possible with your contributions.

Wishing our readers a very happy and prosperous year 2015!

[1] Leslie Citrome. Impact Factor? Shmimpact Factor! The Journal Impact Factor, Modern Day Literature Searching, and the Publication Process. Psychiatry (Edgmont). May 2007; 4(5): 54-57. Published online May 2007

\section{(c)) EY-NC-ND Licensed to GIRI}

How to cite this article: Arora S. A long way to go [Editorial]. Int J High Dilution Res [online]. 2014 [cited YYYY Month dd]; 13(49): 187-188. Available from: http://www.feg.unesp.br/ ojs/index.php/ijhdr/article/view/757/737 